\title{
Hormonal Defects Are Common during Puumala Hantavirus Infection and Associate with Disease Severity and Biomarkers of Altered Haemostasis
}

\author{
Marlene Tarvainen ${ }^{1,2,3, *}$, Satu Mäkelä ${ }^{1,2}$, Outi Laine ${ }^{1,2}$, Ilkka Pörsti ${ }^{1,2}{ }^{\oplus}$, Sari Risku ${ }^{3}$, Onni Niemelä ${ }^{4}$, \\ Jukka Mustonen 1,2 and Pia Jaatinen 1,2,3 \\ 1 Department of Internal Medicine, Tampere University Hospital, 33520 Tampere, Finland; \\ satu.m.makela@pshp.fi (S.M.); outi.laine@pshp.fi (O.L.); ilkka.porsti@tuni.fi (I.P.); \\ jukka.mustonen@tuni.fi (J.M.); pia.jaatinen@tuni.fi (P.J.) \\ 2 Faculty of Medicine and Health Technology, Tampere University, 33520 Tampere, Finland \\ 3 Division of Internal Medicine, Seinäjoki Central Hospital, 60220 Seinäjoki, Finland; sari.risku@epshp.fi \\ 4 Laboratory and Medical Research Unit, Seinäjoki Central Hospital, 60220 Seinäjoki, Finland; \\ onni.niemela@epshp.fi \\ * Correspondence: marlene.tarvainen@pshp.fi
}

check for updates

Citation: Tarvainen, M.; Mäkelä, S.; Laine, O.; Pörsti, I.; Risku, S.;

Niemelä, O.; Mustonen, J.; Jaatinen, P. Hormonal Defects Are Common during Puumala Hantavirus Infection and Associate with Disease Severity and Biomarkers of Altered Haemostasis. Viruses 2021, 13, 1818. https://doi.org/10.3390/v13091818

Academic Editor: Kay Faaberg

Received: 13 July 2021

Accepted: 10 September 2021

Published: 13 September 2021

Publisher's Note: MDPI stays neutral with regard to jurisdictional claims in published maps and institutional affiliations.

Copyright: (c) 2021 by the authors. Licensee MDPI, Basel, Switzerland. This article is an open access article distributed under the terms and conditions of the Creative Commons Attribution (CC BY) license (https:/ / creativecommons.org/licenses/by/ $4.0 /)$.

\begin{abstract}
Central and peripheral hormone deficiencies have been documented during and after acute hantavirus infection. Thrombocytopenia and coagulation abnormalities are common findings in haemorrhagic fever with renal syndrome (HFRS). The associations between coagulation and hormonal abnormalities in HFRS have not been studied yet. Forty-two patients diagnosed with Puumala virus (PUUV) infection were examined during the acute phase and on a follow-up visit approximately one month later. Hormonal defects were common during acute PUUV infection. Overt (clinical) hypogonadism was identified in $80 \%$ of the men and approximately $20 \%$ of the patients had overt hypothyroidism. At the one-month follow-up visit, six patients had central hormone deficits. Acute peripheral hormone deficits associated with a more severe acute kidney injury (AKI), longer hospital stay and more severe thrombocytopenia. Half of the patients with bleeding symptoms had also peripheral hormonal deficiencies. Patients with free thyroxine levels below the reference range had higher D-dimer level than patients with normal thyroid function, but no thromboembolic events occurred. Acute phase hormonal abnormalities associate with severe disease and altered haemostasis in PUUV infection.
\end{abstract}

Keywords: hantavirus; puumala virus; HFRS; hormonal defect; AKI; hypogonadism; hypothyroidism; coagulation; fibrinolysis

\section{Introduction}

Hantavirus infections present with two distinct clinical syndromes: a haemorrhagic fever with renal syndrome (HFRS) in Europe and Asia, and a hantavirus cardiopulmonary syndrome (HCPS) in North and South America [1]. PUUV is the most common hantavirus in Europe, causing a mild form of HFRS, also called nephropathia epidemica [1,2]. The reservoir host of PUUV is the bank vole (Myodes glareolus) [2]. In Finland the seroprevalence of PUUV infection in adult population is about $12.5 \%$ [3], and approximately 1000-3000 serologically verified infections occur annually [1,2].

The clinical course of PUUV infection is usually mild but can vary from subclinical to fatal [2]. Mortality is low, approximately $0.1 \%$. The typical symptoms of PUUV infection include fever, headache, visual disturbances, nausea, backache, and abdominal pain. Serious haemorrhages are rare, but mild bleeding manifestations, such as conjunctival bleeding, petechiae, or epistaxis, occur in about one-third of the patients [2,4]. Transient acute kidney injury (AKI), thrombocytopenia and increased vascular permeability leading to capillary leakage are typical findings in PUUV infection. 
Increased platelet consumption is a central mechanism leading to thrombocytopenia in acute HFRS [2,5]. Platelet activation, enhanced thrombin formation and fibrinolysis together with intravascular coagulation have all been documented [5-7]. Furthermore, high mean platelet volume (MPV), immature platelet fraction (IPF\%), and serum thrombopoietin level have been reported, indicating active thrombopoiesis during thrombocytopenia in acute PUUV infection [6,7].

Case reports have been published on hypophyseal haemorrhage and panhypopituitarism during acute PUUV infection [8-13]. PUUV antigens have also been detected in the pituitary of a patient with a fatal HFRS [9]. Central and peripheral hormone deficiencies have been identified during both acute HFRS and months or even years later [8-12,14-17]. In a previous retrospective study [15] serum cortisol and prolactin levels were higher and serum testosterone concentrations lower during acute PUUV infection, when compared with the corresponding values measured three months later. These acute hormonal alterations were related to the severity of AKI and inflammation.

An increased tendency for bleeding has been reported among patients with severe hypothyroidism, while mainly a thrombotic tendency and a hypercoagulable state have been related to other endocrine disorders (e.g., endogenous hypercortisolism, hypogonadotropic hypogonadism, subclinical or mild hypothyroidism, hyperthyroidism, growth hormone deficiency, acromegaly, hyperprolactinaemia) $[18,19]$. The associations between hormonal deficiencies and platelet or coagulation abnormalities in HFRS have not been studied previously.

The first objective of the present study was to study, in a prospective setting, the hormonal abnormalities during an acute PUUV infection and at a follow-up visit one month later. The second objective was to investigate the association of the hormonal alterations with the severity of acute PUUV infection. Thirdly, we wanted to examine whether the hormonal abnormalities are related to the decreased platelet count and enhanced thrombin formation, fibrinolysis, and thrombopoiesis during acute PUUV infection.

\section{Materials and Methods}

\subsection{Patients}

The study consisted of a prospectively collected cohort of 42 consecutive patients with a serologically confirmed acute PUUV infection [20], treated at Tampere University Hospital or Seinäjoki Central Hospital, Finland, during the years 2010-2017. Thirty of them have participated in our previous study evaluating platelet formation and functions during PUUV infection [7]. Every patient gave a written informed consent before enrolments in the study and the Ethics Committee of Tampere University Hospital approved the study protocol (R09206, accessed on 10 December 2009 and R15007, accessed on 14 January 2015).

The median age of the patients was 45 years (range 21 to 67 years), and 27 (64\%) of them were male. Nineteen patients had concomitant diseases, including arterial hypertension $(n=7)$, diabetes (Type $1, n=1$; Type $2, n=3)$, coronary artery disease $(n=2)$, hypercholesterolaemia $(n=3)$, sleep apnoea $(n=2)$, coeliac disease $(n=2)$; and hereditary spherocytosis with splenectomy [21], hypothyroidism, gastro-oesophageal reflux disease, ulcerative colitis, spondylarthritis, chronic obstructive pulmonary disease, asthma, prostatic hyperplasia, and glaucoma one of each.

One female patient used oral contraception, four patients had a hormonal intrauterine device and one patient used postmenopausal oestrogen replacement therapy. Postmenopausal women $(n=6)$ and premenopausal women with hormonal medications $(n=4)$ were excluded from the analyses of hypogonadism. All the hormone measurements, however, were included in the comparison of hormone levels between the acute PUUV infection and one month after the acute disease. No other medications that could possibly alter plasma hormone concentrations were used during the study. None of the patients were on immunosuppressive or anticoagulation therapy. Two patients used anti-platelet therapy (acetylsalicylic acid) at the time of hospital admission, but the medication was discontinued 
until discharge from hospital. Otherwise, the patients were on their regular medications throughout the study.

\subsection{Study Protocol}

A detailed past and current medical history was obtained, and a careful physical examination was performed. Blood specimens were collected between 7.30 and 9.30 a.m. Laboratory samples for plasma creatinine, C-reactive protein (CRP), and blood cell counts were measured repeatedly, as clinically needed. The highest plasma creatinine concentration measured during the hospital stay reflects the severity of PUUV-induced AKI. The difference between the maximum and minimum body weight during the hospital stay (weight change) reflects the severity of AKI and the phenomenon of capillary leakage. Blood leukocyte count and plasma CRP level reflect the degree of inflammation during the acute infection, and the lowest platelet count measured illustrates the patient's risk for bleeding. The length of hospital stay reflects the overall severity of illness.

The acute-phase blood samples for the assessment of thrombin formation, fibrinolysis and thrombopoiesis $(n=27)$, and for the hormone analyses $(n=40)$ were collected on the first morning after hospital admission, a median of 7 days (4 to 12 days) after the onset of fever. Forty patients attended the follow-up visit, approximately one month (17 to 71 days) after discharge from hospital.

\subsection{Laboratory Measurements}

The blood cell counts, plasma creatinine and CRP concentrations were measured by standard laboratory methods at Fimlab Laboratories, Tampere. Plasma D-dimer and prothrombin fragments $(\mathrm{F} 1+2)$, mean platelet volume $(\mathrm{MPV})$, and immature platelet fraction $(\mathrm{IPF} \%)$, and serum thrombopoietin levels were measured as described in detail previously [5,7]. Hormone analyses were measured by accredited methods at Fimlab Laboratories, Tampere (detailed methodological data in Supplementary methods S2).

\subsection{Statistics}

The highest and the lowest values of the various variables measured during hospitalisation for each patient were designated as the maximum and minimum values, respectively. To describe the data, median, minimum, and maximum values are given for continuous variables, and numbers and percentages for categorical variables. Categorical data were analysed by the Chi-square test or the Fisher exact test, as appropriate. Continuous numerical data were analysed by the Kruskal-Wallis test, and after a statistically significant test result, post hoc comparisons between the groups were performed using the Mann-Whitney $\mathrm{U}$ test. The Wilcoxon signed-rank test was used for evaluating changes in serum hormone levels between the acute and the follow-up visit. The Spearman rank correlation coefficient was used for correlations between continuous variables. A two-sided $p$-value of less than 0.05 was regarded as statistically significant, and the Bonferroni correction was applied in all post hoc analyses. IBM SPSS Statistics for Windows, Version 26.0 (IBM Corporation, Armonk, NY, USA) was used for the statistical analyses.

\section{Results}

The basic clinical characteristics and laboratory findings of the 42 patients with acute PUUV infection are presented in Table 1. Fever lasted for a median of 9 days ( 3 to 16 days). None of the patients were diagnosed with a bacterial infection. Almost all patients (95\%) presented with thrombocytopenia (platelet count below $150 \times 10^{9} / \mathrm{L}$ ), but bleeding symptoms (nasal bleeding, haemoptysis, haematochezia or melaena, petechiae) occurred in only eight patients $(22 \%)$, whilst major bleeding complications were not observed. None of the patients suffered from clinical thromboembolic events.

Thirty-nine (93\%) of the patients had AKI (maximum plasma creatinine level $>100 \mu \mathrm{mol} / \mathrm{L}$ for males and $>90 \mu \mathrm{mol} / \mathrm{L}$ for females) during the acute PUUV infection. Two patients received transient haemodialysis treatment. Clinical shock (defined as typical 
clinical symptoms of shock and systolic blood pressure $<90 \mathrm{mmHg}$ ) was diagnosed in four patients. One male patient with a previous splenectomy due to hereditary spherocytosis [21] and another male patient were treated at the intensive care unit due to severe clinical course of PUUV infection. One patient suffered from a Guillain-Barré syndrome (probably induced by PUUV infection) and was treated with plasmapheresis at the stroke unit. Due to their critical illnesses, acute-phase study samples were not obtained from the patients with the spherocytosis and the Guillain-Barré syndrome. All patients recovered completely.

Table 1. Clinical characteristics and laboratory findings of 42 patients with acute Puumala hantavirus infection.

\begin{tabular}{ccc}
\hline Clinical or Laboratory Variable & Median & Range \\
\hline Age (years) & 45 & $21-67$ \\
Sex $(\mathrm{M} / \mathrm{F})$ & & $27 / 15$ \\
BMI $\left(\mathrm{kg} / \mathrm{m}^{2}\right)$ & 26.2 & $21-39$ \\
Length of hospital stay (days) & 7 & $2-22$ \\
Weight change during hospital stay $(\mathrm{kg})$ & -3.6 & $-0.3-(-12.5)$ \\
Min systolic BP $(\mathrm{mmHg})$ & 112 & $60-154$ \\
Min haematocrit & 0.36 & $0.25-0.43$ \\
Max haematocrit & 0.44 & $0.37-0.66$ \\
Min platelet count $\left(\times 10^{9} / \mathrm{L}\right)$ & 50 & $4-389$ \\
Max leukocyte count $\left(\times 10^{9} / \mathrm{L}\right)$ & 10.7 & $4.2-45.0$ \\
Max level of plasma CRP $(\mathrm{mg} / \mathrm{L})$ & 68 & $16-244$ \\
Max plasma creatinine $(\mu \mathrm{mol} / \mathrm{L})$ & 297 & $71-983$ \\
Plasma D-dimer $(\mathrm{mg} / \mathrm{L})^{*}$ & 2.8 & $0.6-34.0$ \\
Mean platelet volume $(\mathrm{fL}) *$ & 774 & $284-1875$ \\
IPF $(\%)$ & 11.0 & $9.4-13.1$ \\
Plasma prothrombin fragments $(\mathrm{F} 1+2)(\mathrm{pmol} / \mathrm{L}) *$ & 7.3 & $1.8-23.8$ \\
Serum thrombopoietin $(\mathrm{pg} / \mathrm{mL}) *$ & 207 & $56-1258$ \\
\hline
\end{tabular}

Abbreviations: $\mathrm{M}=$ male, $\mathrm{F}=$ female, $\mathrm{BMI}=$ body mass index, $\mathrm{BP}=$ blood pressure, $\mathrm{CRP}=\mathrm{C}$-reactive protein $\mathrm{IPF}=$ immature platelet fraction, $\min =$ minimum, $\max =$ maximum. Reference values: Haematocrit $0.39-0.50$ for males and 0.35-0.46 for females, platelet count 150-360 × 109 / L, leukocyte count 3.4-8.2 × $10^{9} / \mathrm{L}, \mathrm{CRP}<10 \mathrm{mg} / \mathrm{L}$, creatinine 60-100 $\mu \mathrm{mol} / \mathrm{L}$ for males and 50-90 $\mu \mathrm{mol} / \mathrm{L}$ for females, D-dimer $\leq 0.5 \mathrm{mg} / \mathrm{L}, \mathrm{F} 1+\mathrm{F} 2$ 69-229 pmol/L, mean platelet volume 9-12 fL, and immature platelet fraction 1-5\%. Serum thrombopoietin level depends on the platelet count. * Blood samples for the assessment of thrombin formation, fibrinolysis and thrombopoiesis were collected from 27 patients.

\subsection{Hormonal Alterations during Acute PUUV Infection}

During the acute PUUV infection, serum cortisol and prolactin (PRL) levels were significantly higher, and serum insulin-like growth factor 1 (IGF-1), follicle stimulating hormone (FSH), luteinising hormone (LH) and testosterone (Testo) levels lower than the corresponding levels at the follow-up visit one month later (Table 2). Plasma free thyroxine (fT4) concentrations were significantly lower and thyrotropin (TSH) slightly higher during the acute phase, compared with the levels at the one-month visit (Table 2).

Altogether 25 out of $40(63 \%)$ patients had overt defects of the gonadal or thyroid axis during the acute PUUV infection. Twenty-one patients (53\%) had central hormone defects, while overt peripheral deficits were observed in 6 patients $(15 \%)$, and subclinical peripheral deficits in 5 patients (13\%) (Figure 1). Eight patients had two different hormonal defects at the same time.

The acute hormone deficits were more common and more severe in male than in female patients. Twenty out of the $25(80 \%)$ male patients, whose hormone levels were analysed in the acute phase, had overt peripheral $(n=3,12 \%)$ or central $(n=17,68 \%)$ hypogonadism, while two out of five ( $40 \%$ ) premenopausal women without hormonal contraception had central hypogonadism. Overt thyroid axis defects (fT4 below the reference range) were seen in approximately $20 \%$ of the patients and these defects, as well, were more frequent in male than in female patients ( $28 \%$ of men having clinical hypothyroidism vs. $13 \%$ of women). Plasma thyroid peroxidase antibody (TPOAb) level was above the reference range in four $(10 \%)$ patients, none of them having overt peripheral hypothyroidism. 
Table 2. Serum and plasma hormone levels during acute Puumala hantavirus infection and on a follow-up visit one month after discharge from hospital.

\begin{tabular}{|c|c|c|c|c|c|c|}
\hline \multirow[b]{2}{*}{ All patients } & \multicolumn{2}{|c|}{ Acute Phase $(n=40) * *$} & \multicolumn{2}{|c|}{ Follow-Up Visit $(n=40) * *$} & \multirow[t]{2}{*}{$p$-Value ${ }^{\text {a }}$} & \multirow[t]{2}{*}{ Reference Range } \\
\hline & Median & Range & Median & Range & & \\
\hline Cortisol (nmol/L) & 441 & $180-1454$ & 298 & $128-554$ & $<0.001$ & $170-500$ \\
\hline $\mathrm{ACTH}(\mathrm{ng} / \mathrm{L})$ & 18.0 & $5.6-64.0$ & 16.5 & $4.0-72.0$ & 1.000 & $0.0-45.0$ \\
\hline PRL $(\mathrm{mU} / \mathrm{L})$ & 421 & $109-3415$ & 205 & $98-551$ & $<0.001$ & * \\
\hline Free thyroxine (pmol/L) & 13.0 & $4.8-17.5$ & 15.0 & $9.8-19.8$ & 0.001 & $11.0-22.0$ \\
\hline Thyrotropin (mU/L) & 3.1 & $0.57-9.10$ & 2.20 & $0.33-6.30$ & 0.028 & $0.27-4.2$ \\
\hline $\mathrm{TPO}-\mathrm{Ab}(\mathrm{kU} / \mathrm{L})$ & 13 & 4-108 & 13 & 5-103 & 0.656 & $<34$ \\
\hline Growth hormone (GH) (ug/L) & 0.90 & $0.1-21.5$ & 0.3 & $0.03-8.00$ & 0.220 & $*$ \\
\hline IGF-1 (nmol/L) & 13.0 & $2.9-29.0$ & 23.0 & $13.0-37.0$ & $<0.001$ & * \\
\hline \multicolumn{7}{|l|}{ Males $(n=25)$} \\
\hline Testosterone (nmol/L) & 4.6 & $0.2-18.0$ & 13.6 & $6.7-29.5$ & $<0.001$ & $10.0-38.0$ \\
\hline $\mathrm{LH}(\mathrm{U} / \mathrm{L})$ & 3.8 & $0.4-18.0$ & 4.7 & $2.5-14.2$ & 0.027 & $1.7-8.6$ \\
\hline PRL (mU/L) & 359.0 & $109-1283$ & 186 & $98-533$ & $<0.001$ & $86-324$ \\
\hline \multicolumn{7}{|l|}{ Females $(n=15)$} \\
\hline Oestradiol (nmol/L) & 0.16 & $0.05-2.47$ & 0.20 & $0.02-1.08$ & 0.551 & * \\
\hline $\mathrm{FSH}(\mathrm{U} / \mathrm{L})$ & 4.2 & $1.4-63.4$ & 6.4 & $3.4-69.6$ & 0.001 & * \\
\hline PRL (mU/L) & 471 & $313-3415$ & 266 & $131-551$ & 0.001 & $102-496$ \\
\hline
\end{tabular}

${ }^{a}$ Comparison between the hormone levels measured in the acute phase and on the follow-up visit, Wilcoxon signed-rank test. ${ }^{*}$ Oestradiol and FSH values were evaluated according to the phase of menstrual cycle and GH, IGF-1 and PRL values according to age or sex, as appropriate. ${ }^{* *}$ Hormone measurements were not available in two patients in the acute phase and in two patients on the follow-up visit.

Five patients had a relatively low serum cortisol level $(<300 \mathrm{nmol} / \mathrm{L})$ during the acute illness. All of these patients had also transient hyponatraemia (plasma sodium level $122-137 \mathrm{mmol} / \mathrm{L}$ ) in the absence of significant hypotension (minimum blood pressure 101-135 /63-78 mmHg). The serum IGF-1 concentration was below the reference range in 10 patients $(25 \%)$, and the IGF-1:GH-ratio (insulin-like growth factor 1: growth hormoneratio) in the whole cohort was lower during the acute phase (median 12, range 0.4 to 130) than at the control visit (median 77, range 3.8 to 630).

Acute phase $(\mathrm{N}=40)$

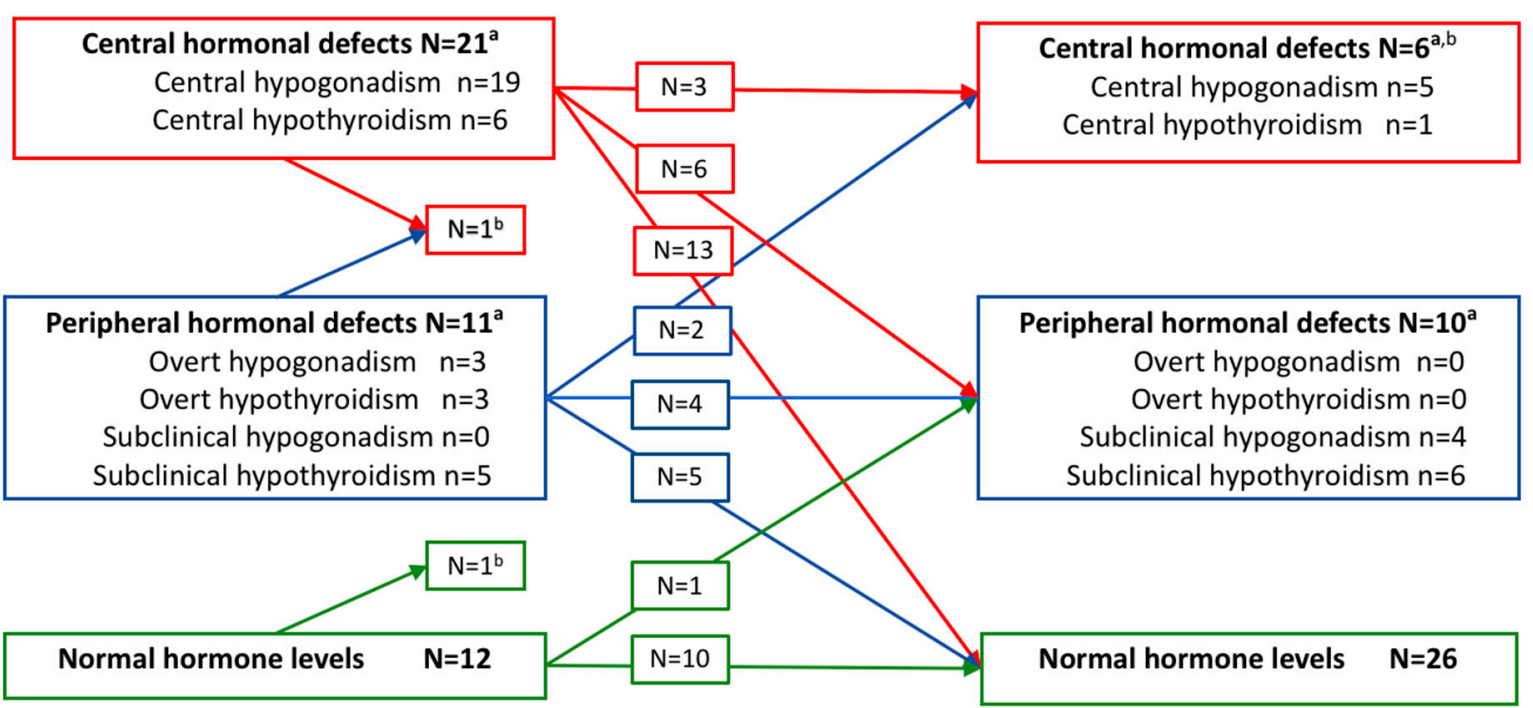

Figure 1. Central and peripheral hormone deficits in 40 patients during acute PUUV infection and at the one-month follow-up visit. a Eight patients had two different hormone defects in the acute phase, and two patients at the follow-up visit, respectively. ${ }^{b}$ Hormone measurements were not available for two patients in the acute phase and two patients at the follow-up visit. $\mathrm{N}=$ Number of patients, $\mathrm{n}=$ number of hormonal defects. 


\subsection{Hormonal Abnormalities at the Follow-Up Visit}

Overt gonadal or thyroid axis defects were still found in six of the $40(15 \%)$ patients approximately one month after discharge from hospital. All of them had a central hormone deficit. Four out of 25 men (16\%) and one premenopausal woman had central hypogonadism. This woman developed panhypopituitarism and polyendocrinopathy a few months after the acute PUUV infection [17]. Only one patient had central hypothyroidism (low fT4, normal TSH) at the one-month follow-up visit. In addition, four men (16\%) had subclinical peripheral hypogonadism (normal Testo, elevated LH level), and six patients $(15 \%)$ had subclinical peripheral hypothyroidism (normal fT4, elevated TSH). Plasma $\mathrm{TPOAb}$ concentration was above the reference range in three patients $(8 \%)$, who also had had elevated TPOAbs during the acute PUUV infection. One of these patients had subclinical peripheral hypothyroidism. Two patients (male and female) $(6 \%)$ had low cortisol (128-161 nmol/L) and normal ACTH levels (4-13 ng/L) at the follow-up visit, one of them having symptoms related to low cortisol level (fatigue, decreased muscle strength). An overview of the clinical and subclinical hormonal deficits during the acute PUUV infection and at the follow-up visit are presented in Figure 1.

Elevated hormone levels were observed in a few patients at the follow-up visit. Three patients $(8 \%)$ had a high serum cortisol level, associated with a plasma ACTH level within the reference range. The PRL concentration was slightly elevated $(344-535 \mathrm{mU} / \mathrm{L})$ in six patients $(17 \%)$. One of these patients had central hypogonadism and subclinical peripheral hypothyroidism, one had subclinical peripheral hypothyroidism, and two patients had subclinical hypogonadism. Four out of 15 women $(27 \%)$ and one man had an elevated IGF-1 concentration (26-37 $\mathrm{nmol} / \mathrm{L})$.

\subsection{Associations of Hormone Levels with the Severity of PUUV Infection}

There were several significant correlations between the hormone concentrations measured in the acute phase and the markers of PUUV infection severity. The strongest correlations between the hormone levels and the markers of disease severity are illustrated in Figure 2.

During the acute phase, there were significant differences in the markers of severity of PUUV infection between the patients with overt (clinical) hormonal deficiencies and those with normal hormone levels (Table 3). Males had overt hormone defects more often than females (Table 3).

No differences were found in the age distribution, clinical picture, or basic laboratory findings during acute PUUV infection between the six patients who presented with overt hormone deficiencies at the one-month follow-up visit and those with normal hormone levels (data not shown).

\subsection{Associations of Hormone Levels with Platelets, Thrombin Formation and Fibrinolysis}

The minimum platelet counts were significantly lower and the IPF\% values higher in patients with peripheral hormone deficits than in those with normal hormone levels during acute PUUV infection (Table 4). Median levels of prothrombin fragments and D-dimer were also numerically higher in patients with peripheral hormone deficits, but the difference was not statistically significant. Nevertheless, the median and maximum D-dimer levels were more than four times higher among the patients with peripheral hormonal deficiencies, compared to the patients with normal hormone levels (Table 4).

Serum cortisol concentration was the hormone level showing strongest associations with the platelet variables, as well as with the markers of thrombin formation and fibrinolysis (Figure 3). GH concentrations correlated inversely with the minimum platelet count $(\mathrm{r}=-0.468, p=0.002)$, and the IGF- 1 and fT4 levels with IPF $\%(r=-0.501, p=0.006$ and $\mathrm{r}=-0.478, p=0.009$, respectively). 

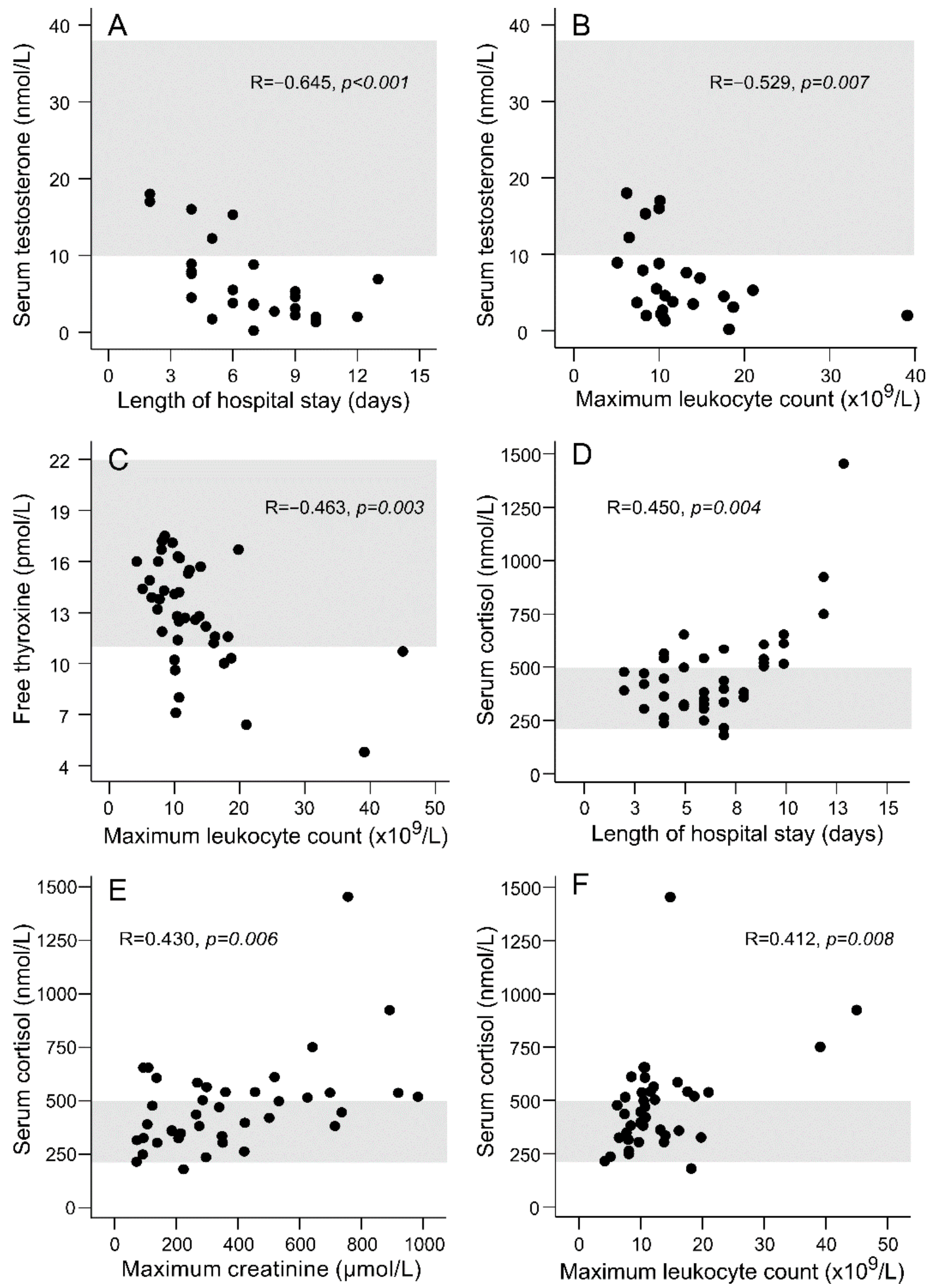

Figure 2. Scatter plots illustrating the correlations between serum testosterone level and the length of hospital stay (A) and maximum leukocyte count (B), between free thyroxine level and the maximum leukocyte count (C), between serum cortisol level and length of hospital stay (D), maximum creatinine level (E) and maximum leukocyte count (F) in patients with acute Puumala hantavirus infection. The reference range for each hormone is marked with shading. 
Table 3. Clinical findings during acute Puumala hantavirus infection in patients with normal hormone levels, and in those with overt central or peripheral hormonal defects.

\begin{tabular}{|c|c|c|c|c|c|c|c|}
\hline & \multicolumn{2}{|c|}{$\begin{array}{l}\text { Normal Hormone Levels } \\
\qquad(n=15)\end{array}$} & \multicolumn{2}{|c|}{$\begin{array}{l}\text { Central Hormonal Defects }{ }^{\text {a }} \\
\qquad(n=19)\end{array}$} & \multicolumn{2}{|c|}{$\begin{array}{l}\text { Peripheral Hormonal } \\
\text { Defects }{ }^{b}(n=6)\end{array}$} & \multirow[t]{2}{*}{$\begin{array}{l}\text { Over-All } \\
p \text {-Value }\end{array}$} \\
\hline & Median & Min-max & Median & Min-max & Median & Min-max & \\
\hline Age (years) & 45 & $21-63$ & 46 & $28-67$ & 38 & $25-67$ & 0.741 \\
\hline $\operatorname{Sex}(\mathrm{M} / \mathrm{F})$ & $3 / 12$ & & $17 / 2$ & & $5 / 1$ & & $0.001^{c}$ \\
\hline $\mathrm{BMI}\left(\mathrm{kg} / \mathrm{m}^{2}\right)$ & 26 & $22-39$ & 26 & $21-37$ & 25 & $23-35$ & 0.976 \\
\hline Length of HS (days) & 6 & $2-10$ & $6^{\#}$ & $2-12$ & $9 *$ & $7-13$ & $0.020^{c}$ \\
\hline $\begin{array}{l}\text { Weight change } \\
\text { during HS (kg) }\end{array}$ & -1.95 & $-0.3-(-12.5)$ & -5.6 & $-0.3-(-11.3)$ & -5.6 & $-3.2-(-7.0)$ & 0.089 \\
\hline $\begin{array}{l}\text { Min diuresis } \\
\text { (ml/day) }\end{array}$ & 1035 & $300-5100$ & 805 & 150-2320 & 345 & $20-1200$ & 0.143 \\
\hline $\begin{array}{l}\text { Min systolic BP } \\
(\mathrm{mmHg})\end{array}$ & 108 & 80-139 & 110 & $60-154$ & 117 & $86-125$ & 0.939 \\
\hline $\begin{array}{l}\text { Min platelet count } \\
\left(\times 10^{9} / \mathrm{L}\right)\end{array}$ & 67 & $27-389$ & 42 & $4-141$ & $30 * *$ & $5-66$ & $0.010^{c}$ \\
\hline $\begin{array}{l}\text { Max leukocyte count } \\
\qquad\left(\times 10^{9} / \mathrm{L}\right)\end{array}$ & 8.4 & $4.2-16.2$ & 10.7 & $5.1-39.1$ & 12.6 & $10.0-45.0$ & 0.125 \\
\hline Max CRP (mg/L) & 50 & $16-142$ & 74 & $21-244$ & 78 & 57-204 & 0.201 \\
\hline $\begin{array}{l}\text { Max creatinine } \\
(\mu \mathrm{mol} / \mathrm{L})\end{array}$ & 268 & $71-714$ & 339 & 93-983 & $727^{* * *}$ & 274-919 & $0.027^{c}$ \\
\hline
\end{tabular}

Abbreviations: $\mathrm{M}=$ male; $\mathrm{F}=$ female; $\mathrm{BMI}=$ body mass index; $\mathrm{BP}=$ blood pressure; $\mathrm{CRP}=\mathrm{C}$-reactive protein, $\mathrm{HS}=$ hospital stay, min = minimum $\max =$ maximum. ${ }^{\mathrm{a}}$ Central hypogonadism or hypothyroidism, ${ }^{\mathrm{b}}$ Overt peripheral hypogonadism or hypothyroidism. c Statistically significant difference between the three groups, Kruskal-Wallis test for numerical variables, Fisher exact test for Sex." Patients with central hormone defects had a shorter hospital stay than patients with peripheral hormone defects (adjusted $p=0.042$ ). Patients with peripheral hormone defects had * a longer hospital stay (adjusted $p=0.019$ ), ** lower minimum platelet counts (adjusted $p=0.012$ ) and $* * *$ higher maximum creatinine levels (adjusted $p=0.027$ ), compared to patients with normal hormone values.
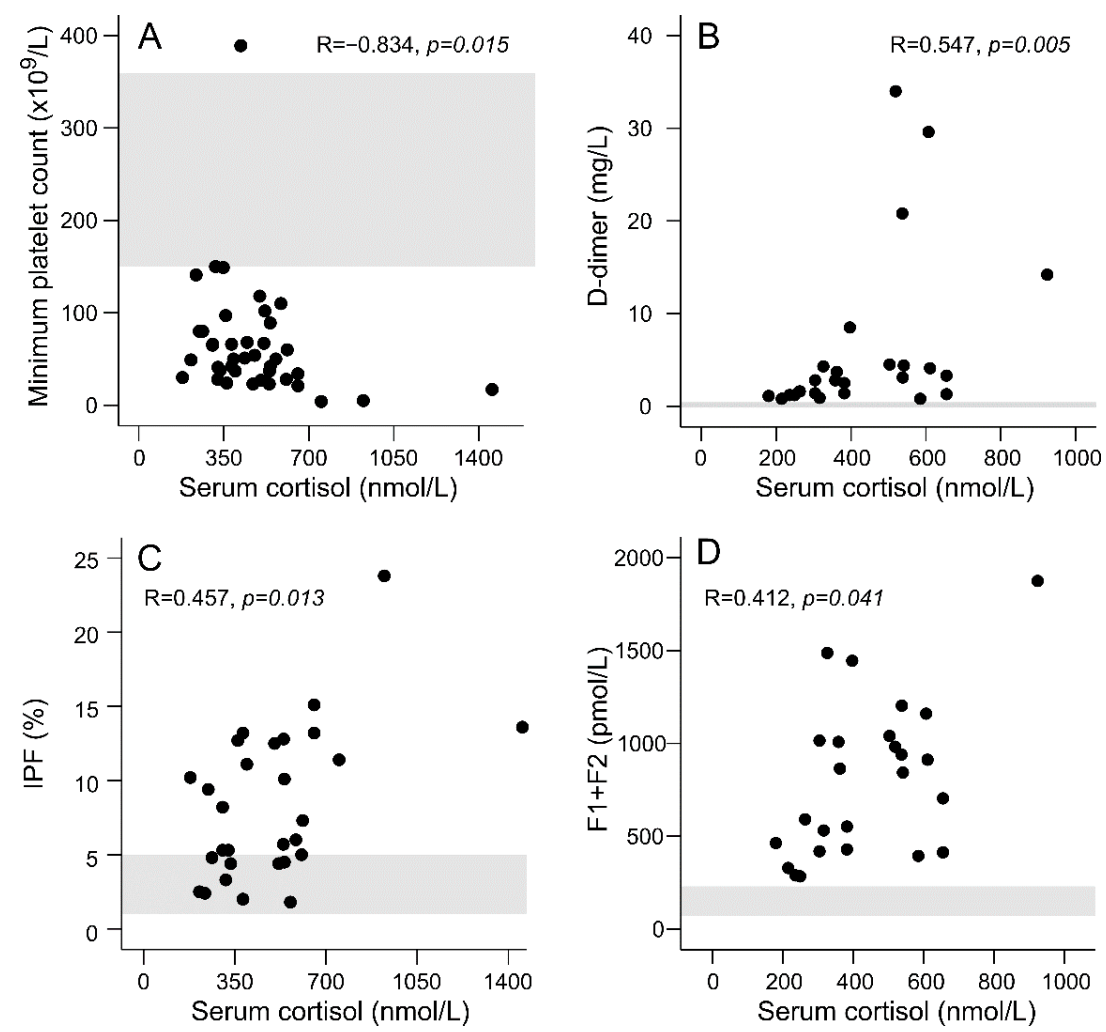

Figure 3. Scatter plots illustrating the correlations between serum cortisol level and the minimum platelet count (A), D-dimer (B), immature platelet fraction (IPF; C) and plasma prothrombin fragments $(\mathrm{F} 1+\mathrm{F} 2 ; \mathrm{D})$ in patients with acute Puumala hantavirus infection. The reference ranges are marked with shading. 
Table 4. Platelet count and markers of thrombopoiesis, thrombin formation and fibrinolysis during acute PUUV infection in patients with normal hormone levels, and in those with overt central or peripheral hormonal defects.

\begin{tabular}{|c|c|c|c|c|c|c|c|c|c|c|}
\hline & \multicolumn{3}{|c|}{$\begin{array}{l}\text { Normal Hormone Levels } \\
\qquad(n=15)\end{array}$} & \multicolumn{3}{|c|}{$\begin{array}{l}\text { Central Hormonal Defects }{ }^{a} \\
\qquad(n=19)\end{array}$} & \multicolumn{3}{|c|}{$\begin{array}{l}\text { Peripheral Hormonal Defects } b \\
\qquad(n=6)\end{array}$} & \multirow[t]{2}{*}{$\begin{array}{l}\text { Over-All } \\
p \text {-Value }\end{array}$} \\
\hline & $\mathrm{n}$ & Median & Min-max & $\mathrm{n}$ & Median & Min-max & $\mathrm{n}$ & Median & Min-max & \\
\hline $\begin{array}{l}\text { Min platelet count } \\
\qquad\left(\times 10^{9} / \mathrm{L}\right)\end{array}$ & 15 & 67 & $27-389$ & 19 & 42 & $4-141$ & 6 & $30 *$ & $5-66$ & $0.010^{c}$ \\
\hline MPV (fL) ${ }^{d}$ & 9 & 10.8 & $9.5-12.3$ & 13 & 11.4 & $9.4-13.1$ & 4 & 12.5 & $10.9-12.8$ & 0.059 \\
\hline $\operatorname{IPF}(\%)^{d}$ & 8 & 5.3 & $1.8-12.5$ & 15 & 7.3 & $2.4-15.1$ & 6 & $13.0 * *$ & $5.7-23.8$ & $0.013^{c}$ \\
\hline $\begin{array}{l}\text { Thrombopoietin } \\
(\mathrm{pg} / \mathrm{mL})^{d}\end{array}$ & 9 & 128 & 59-347 & 11 & 151 & $56-648$ & 6 & 268 & $162-1258$ & 0.181 \\
\hline $\mathrm{F} 1+2(\mathrm{pmol} / \mathrm{L})^{\mathrm{d}}$ & 8 & 429 & 284-1040 & 12 & 773.5 & 289-1487 & 5 & 1203 & $552-1875$ & 0.088 \\
\hline D-Dimer $(m g / L) d$ & 8 & 1.9 & $0.8-4.5$ & 12 & 3.5 & $1.1-34.0$ & 5 & 8.5 & $1.4-20.8$ & 0.068 \\
\hline
\end{tabular}

Abbreviations: MPV = mean platelet volume; IPF = immature platelet fraction \%; F1 + $2=$ plasma prothrombin fragments. Reference values: platelet count 150-360 × 109 /L, MPV 9.0-12.0 fL, IPF\% 1.0-5.0\%, F1+F2 69-229 pmol/L and D-dimer $\leq 0.5 \mathrm{mg} / 1$. Serum thrombopoietin level depends on the platelet count. * The minimum platelet counts were significantly lower (adjusted $p=0.012$ ) and ** the IPF\% values higher (adjusted $p=0.010$ ) in patients with peripheral hormone deficits than in those with normal hormone levels. ${ }^{a}$ Central hypogonadism or hypothyroidism, ${ }^{b}$ Overt peripheral hypogonadism or hypothyroidism. ${ }^{c}$ Statistically significant difference between the three groups, Kruskal-Wallis test. ${ }^{d}$ Blood samples for the assessment of thrombin formation, fibrinolysis and thrombopoiesis were collected from 25-29 patients.

The patients with fT4 level below the reference range had higher D-dimer levels than the patients with normal thyroid function (median $14.2 \mathrm{mg} / \mathrm{L}$, range 3.1 to $34.0 \mathrm{mg} / \mathrm{L}$ vs. median $2.1 \mathrm{mg} / \mathrm{L}$, range $0.8-29.6 \mathrm{mg} / \mathrm{L}, p=0.007)$. In patients with hyperprolactinaemia, IPF\% $(11.1 \%,(2.5-15.1 \%)$ vs. 5.2\%, (1.8-23.8\%), $p=0.046)$ and MPV (11.9 fL, $(10.4-13.1 \mathrm{fL})$ vs. $10.9 \mathrm{fL},(9.4-12.3 \mathrm{fL}), p=0.046)$ were higher than in normo-prolactinaemic patients.

\subsection{Associations between Bleeding Symptoms, Markers of Disease Severity and Hormones}

During the acute PUUV infection, eight patients presented with mild bleeding symptoms. The bleeding symptoms associated with a more severe course of the infection, indicated by a longer hospital stay (median 8 days, range 7 to 22 days vs. median 6 days, range 3 to 10 days, $p<0.001)$, lower minimum systolic blood pressure $(92 \mathrm{mmHg}$ $(60-119 \mathrm{mmHg})$ vs. $114 \mathrm{mmHg}(80-136 \mathrm{mmHg}), p=0.003)$, and lower platelet counts $\left(24 \times 10^{9} / \mathrm{L}\left(4-97 \times 10^{9} / \mathrm{L}\right)\right.$ vs. $\left.60 \times 10^{9} / \mathrm{L}\left(21-389 \times 10^{9} / \mathrm{L}\right), p=0.002\right)$.

Bleeding symptoms were more frequent among patients with peripheral hormone defects than in those with normal hormone levels $(67 \%$ vs. $0 \%, p=0.001)$. The patients with bleeding symptoms had lower fT4 levels ( $11.6 \mathrm{pmol} / \mathrm{L}(4.8-14.1 \mathrm{pmol} / \mathrm{L})$ vs. $14.3 \mathrm{pmol} / \mathrm{L}$ $(6.4-17.5 \mathrm{pmol} / \mathrm{L}), p=0.009)$ and higher cortisol levels $(655 \mathrm{nmol} / \mathrm{L}(358-1454 \mathrm{pmol} / \mathrm{L}) \mathrm{vs}$. $401 \mathrm{pmol} / \mathrm{L}(180-655 \mathrm{pmol} / \mathrm{L}), p=0.013)$ than the patients without bleeding symptoms.

\section{Discussion}

In the present study, hormonal defects were common during acute PUUV infection. Two thirds of the patients presented with overt (i.e., clinical) gonadal and thyroid axis defects. Male patients had more central and peripheral hormone defects than female ones. The acute peripheral hormone defects associated with a lower platelet count, more severe AKI and a longer hospital stay, compared to patients with normal hormone levels. Two thirds of the patients with peripheral hormone deficiencies had also mild bleeding symptoms. D-Dimer, a marker of thrombosis and fibrinolysis, was higher in patients with overt hypothyroidism, compared to patients with normal thyroid hormone levels. Six patients had central hormone deficits at the one-month follow-up visit; these hormonal deficiencies were not associated with the severity of acute PUUV infection.

The hormonal disturbances observed in this prospectively studied cohort were mostly in line with the hormone alterations reported in our previous, retrospective study [15]. Hypogonadism was even more prevalent in the present study, $80 \%$ of the male patients having overt hypogonadism, while half of the men were hypogonadal in the previous retrospective study [15]. LH levels were significantly lower in the acute phase than at 
the one-month control visit in the present study, reflecting a predominantly central origin of hypogonadism. Low levels of testosterone (and fT4) were related to leukocytosis in the acute phase. Low testosterone levels also associated with a prolonged hospital stay. Similarly, the degree of gonadal axis suppression has been related to the severity of acute illness in a previous study on patients admitted to critical care units [22].

As expected, serum cortisol level correlated with the severity of acute illness (degree of AKI and leukocytosis, duration of hospital stay) [15]. During viral infections, several cytokines have been shown to activate the hypothalamic-pituitary-adrenal (HPA) axis, leading to an increased release of glucocorticoids from the adrenal cortex [23]. Impaired kidney function may also have contributed to the increased cortisol levels, as the conversion of cortisol to cortisone is reduced during impaired kidney function [24]. The increased HPA axis activity and cortisol levels, in turn, may suppress the activity of the gonadal and thyroid axes [25].

Despite the increased cortisol levels in general, some patients had abnormally low levels of cortisol during the acute illness. Although none of these patients required hydrocortisone substitution during the acute PUUV infection or shortly thereafter, we continue the follow-up of these patients in order to detect possible hypocortisolism or other clinical hormone deficiencies without delay.

Studies on inflammation and thyroid function have shown that cytokines, e.g., IL1 alpha and beta, IL6, TNF alpha, and interferon gamma, downregulate the thyroid hormone synthesis pathway, decreasing the secretion of T4 and triiodothyronine, T3 [26]. During acute illness, previously euthyroid patients may present with low levels of T4 and T3, and elevated levels of reverse T3, all of which gradually normalise as the acute illness subsides [27]. This state called 'euthyroid sick syndrome' or 'nonthyroidal illness syndrome' $[26,27]$, may account for some of the thyroid axis abnormalities observed in the present study.

In the present study, the patients with overt peripheral hormone defects had lower platelet counts and higher IPF\%, compared to patients with normal hormone levels. This implies that despite the decreased platelet count thrombopoiesis is active also in patients with overt hormone deficits during acute PUUV infection [7]. Increased D-dimer and F1 +2 further support ongoing thrombin formation, fibrinolysis and consumption of platelets as the mechanism of thrombocytopenia.

In our study, the patients with hypothyroidism had higher D-dimer levels than euthyroid patients, and fT4 levels correlated inversely with IPF\%, indicating active fibrinolysis and platelet formation in the hypothyroid patients. Furthermore, slightly lower fT4 levels were noted in the patients with mild bleeding symptoms than in those without any bleeding symptoms. Our observations are in line with previous reports regarding the associations between altered haemostasis and thyroid function $[18,19,28]$.

The serum cortisol levels during acute PUUV infection correlated with the levels of Ddimer, prothrombin fragments $\mathrm{F} 1+\mathrm{F} 2$, and $\mathrm{IPF} \%$, and inversely with the minimum platelet count. Increased levels of clotting factors and abnormalities in fibrinolytic parameters have been reported in patients with Cushing's syndrome $[18,19,29,30]$. The coagulation pathway has been reported to be hyperactive [30] and an increased incidence of both venous and arterial thrombotic events has been reported among patients with endogenous hypercortisolism [31,32].

In this study, the balance between thrombin formation and fibrinolysis remained beneficial for patients with overt hormonal defects, as no thrombotic or severe bleeding events occurred. Mild bleeding symptoms were observed in only one fifth of the patients, who suffered from a more severe course of PUUV infection and more peripheral hormone defects, as well as more severe hypercortisolism. A thrombotic tendency has previously been related to several hormonal abnormalities, especially hypothyroidism and hypercortisolism [18,19]. In addition, Swedish studies have shown an increased risk of venous thromboembolism [33], myocardial infarction, and stroke [34] in patients with HFRS. The hormonal alterations noted during acute PUUV infection, e.g., low fT4 and high cortisol 
levels might, in part, protect the patients from major bleeding complications by shifting the haemostatic balance to the prothrombotic direction.

In conclusion, hormonal deficiencies were common during acute PUUV infection. Patients with peripheral hormonal deficiencies had a lower platelet count and higher IPF\%, compared to patients with normal hormone levels, but no severe bleeding complications were observed. Acute peripheral hormone deficits associated with more severe AKI and a longer hospital stay. Most but not all of the acute hormonal defects were normalised by the one-month follow-up visit. As chronic hormonal defects have been diagnosed a few years after PUUV infection in as many as one sixth of patients in previous studies [15,16], we will continue to follow up the patients for the possibility of developing chronic hormone deficiencies that may require hormonal replacement therapy.

Supplementary Materials: The following are available online at https:/ / www.mdpi.com/article/10 .3390/v13091818/s1. Data of original material S1 and Hormone analysis methods S2.

Author Contributions: Conceptualisation, S.M., P.J., O.L., S.R. and J.M.; methodology, M.T., S.M., P.J., O.L., O.N. and J.M.; software, M.T., P.J. and I.P.; validation, S.M. and P.J.; formal analysis, M.T., S.M., I.P. and P.J.; investigation, M.T., S.M., P.J., O.L., S.R., O.N. and J.M.; resources, S.M., P.J., S.R., O.N. and J.M.; data curation, M.T., S.M. and O.L.; writing—original draft preparation, M.T.; writing—review and editing, M.T., P.J., S.M., O.L., I.P., S.R., O.N. and J.M.; visualisation, M.T., I.P. and P.J.; supervision, P.J., S.M., O.L., I.P. and J.M.; project administration, P.J., S.M. and J.M.; funding acquisition, J.M., P.J. and S.M. All authors have read and agreed to the published version of the manuscript.

Funding: This research was financially supported by the Competitive State Research Financing of the Expert Responsibility Area of Tampere University Hospital (5900/3225; MT, PJ and 9V025 OL) and the Medical Research Fund of Seinäjoki Central Hospital (6000/3231; MT, PJ).

Institutional Review Board Statement: The study was conducted according to the guidelines of the Declaration of Helsinki, and approved by the Ethics Committee of Tampere University Hospital (R09206, date 10 December 2009 and R15007, date 14 January 2015).

Informed Consent Statement: Informed consent was obtained from all subjects involved in the study.

Data Availability Statement: Original data are available as Supplementary Material.

Acknowledgments: The authors thank Esko Väyrynen, lecturer, for revising the language of the manuscript. The authors are deeply grateful to research nurses Katriina Ylinikkilä, Niina Rantamäki, Eini Eskola, and Reeta Kulmala for invaluable technical assistance, and specialist in clinical chemistry and laboratory medicine Maria Juujärvi, and clinical microbiologist Kerttu Saha for their invaluable help and advice in laboratory analytics.

Conflicts of Interest: The authors declare no conflict of interest. The funders had no role in the design of the study; in the collection, analyses, or interpretation of data, in the writing of the manuscript, or in the decision to publish the results.

\section{References}

1. Vaheri, A.; Strandin, T.; Hepojoki, J.; Sironen, T.; Henttonen, H.; Makela, S.; Mustonen, J. Uncovering the mysteries of hantavirus infections. Nat. Rev. Microbiol. 2013, 11, 539-550. [CrossRef] [PubMed]

2. Mustonen, J.; Makela, S.; Outinen, T.; Laine, O.; Jylhava, J.; Arstila, P.T.; Hurme, M.; Vaheri, A. The pathogenesis of nephropathia epidemica: New knowledge and unanswered questions. Antivir. Res. 2013, 100, 589-604. [CrossRef] [PubMed]

3. Latronico, F.; Maki, S.; Rissanen, H.; Ollgren, J.; Lyytikainen, O.; Vapalahti, O.; Sane, J. Population-based seroprevalence of Puumala hantavirus in Finland: Smoking as a risk factor. Epidemiol. Infect. 2018, 146, 367-371. [CrossRef]

4. Mustonen, J.; Outinen, T.; Laine, O.; Porsti, I.; Vaheri, A.; Makela, S. Kidney disease in Puumala hantavirus infection. Infect. Dis. 2017, 49, 321-332. [CrossRef]

5. Laine, O.; Mäkelä, S.; Mustonen, J.; Huhtala, H.; Szanto, T.; Vaheri, A.; Lassila, R.; Joutsi-Korhonen, L. Enhanced thrombin formation and fibrinolysis during acute Puumala hantavirus infection. Thromb. Res. 2010, 126, 154-158. [CrossRef]

6. Connolly-Andersen, A.; Sundberg, E.; Ahlm, C.; Hultdin, J.; Baudin, M.; Larsson, J.; Dunne, E.; Kenny, D.; Lindahl, T.L.; Ramstrom, S.; et al. Increased Thrombopoiesis and Platelet Activation in Hantavirus-Infected Patients. J. Infect. Dis. 2015, 212, 1061-1069. [CrossRef] 
7. Laine, O.; Joutsi-Korhonen, L.; Lassila, R.; Koski, T.; Huhtala, H.; Vaheri, A.; Makela, S.; Mustonen, J. Hantavirus infection-induced thrombocytopenia triggers increased production but associates with impaired aggregation of platelets except for collagen. Thromb. Res. 2015, 136, 1126-1132. [CrossRef] [PubMed]

8. Forslund, T.; Saltevo, J.; Anttinen, J.; Auvinen, S.; Brummer-Korvenkontio, M.; Korhonen, A.; Poutiainen, M. Complications of nephropathia epidemica: Three cases. J. Int. Med. 1992, 232, 87-90. [CrossRef]

9. Hautala, T.; Sironen, T.; Vapalahti, O.; Paakko, E.; Sarkioja, T.; Salmela, P.I.; Vaheri, A.; Plyusnin, A.; Kauma, H. Hypophyseal hemorrhage and panhypopituitarism during Puumala Virus Infection: Magnetic Resonance Imaging and detection of viral antigen in the hypophysis. Clin. Infect. Dis. 2002, 35, 96-101. [CrossRef] [PubMed]

10. Settergren, B.; Boman, J.; Linderholm, M.; Wistrom, J.; Hagg, E.; Arvidsson, P.A. A case of nephropathia epidemica associated with panhypopituitarism and nephrotic syndrome. Nephron 1992, 61, 234-235. [CrossRef]

11. Jost, C.; Krause, R.; Graninger, W.; Weber, K. Transient hypopituitarism in a patient with nephropathia epidemica. BMJ Case Rep. 2009, 2009, bcr0220091538. [CrossRef]

12. Pekic, S.; Cvijovic, G.; Stojanovic, M.; Kendereski, A.; Micic, D.; Popovic, V. Hypopituitarism as a late complication of hemorrhagic fever. Endocrine 2005, 26, 79-82. [CrossRef]

13. Valtonen, M.; Kauppila, M.; Kotilainen, P.; Lahdevirta, J.; Svartback, C.M.; Kosunen, O.; Nurminen, J.; Sarkkinen, H.; Brummer-Korvenkontio, M. Four fatal cases of nephropathia epidemica. Scand. J. Infect. Dis. 1995, 27, 515-517. [CrossRef] [PubMed]

14. Partanen, T.; Koivikko, M.; Leisti, P.; Salmela, P.; Paakko, E.; Karttunen, A.; Sintonen, H.; Risteli, L.; Hautala, N.; Vapalahti, O.; et al. Long-term hormonal follow-up after human Puumala hantavirus infection. Clin. Endocrinol. 2016, 84, 85-91. [CrossRef] [PubMed]

15. Makela, S.; Jaatinen, P.; Miettinen, M.; Salmi, J.; Ala-Houhala, I.; Huhtala, H.; Hurme, M.; Porsti, I.; Vaheri, A.; Mustonen, J. Hormonal deficiencies during and after Puumala hantavirus infection. Eur. J. Clin. Microbiol. Infect. Dis. 2010, $29,705-713$. [CrossRef]

16. Stojanovic, M.; Pekic, S.; Cvijovic, G.; Miljic, D.; Doknic, M.; Nikolic-Djurovic, M.; Micic, D.; Hrvacevic, R.; Nesic, V.; Popovic, V. High risk of hypopituitarism in patients who recovered from hemorrhagic fever with renal syndrome. J. Clin. Endocrinol. Metab. 2008, 93, 2722-2728. [CrossRef]

17. Tarvainen, M.; Makela, S.; Mustonen, J.; Jaatinen, P. Autoimmune polyendocrinopathy and hypophysitis after Puumala hantavirus infection. Endocrinol. Diabetes Metab. Case Rep. 2016, 2016, 16-0084. [CrossRef]

18. Franchini, M.; Lippi, G.; Manzato, F.; Vescovi, P.P.; Targher, G. Hemostatic abnormalities in endocrine and metabolic disorders. Eur. J. Endocrinol. 2010, 162, 439-451. [CrossRef]

19. Kyriakakis, N.; Lynch, J.; Ajjan, R.; Murray, R.D. The effects of pituitary and thyroid disorders on haemostasis: Potential clinical implications. Clin. Endocrinol. 2016, 84, 473-484. [CrossRef]

20. Vaheri, A.; Vapalahti, O.; Plyusnin, A. How to diagnose hantavirus infections and detect them in rodents and insectivores. Rev. Med. Virol. 2008, 18, 277-288. [CrossRef] [PubMed]

21. Antonen, J.; Leppanen, I.; Tenhunen, J.; Arvola, P.; Makela, S.; Vaheri, A.; Mustonen, J. A severe case of Puumala hantavirus infection successfully treated with bradykinin receptor antagonist icatibant. Scand. J. Infect. Dis. 2013, 45, 494-496. [CrossRef] [PubMed]

22. Spratt, D.I.; Cox, P.; Orav, J.; Moloney, J.; Bigos, T. Reproductive axis suppression in acute illness is related to disease severity. J. Clin. Endocrinol. Metab. 1993, 76, 1548-1554. [CrossRef] [PubMed]

23. Silverman, M.N.; Pearce, B.D.; Biron, C.A.; Miller, A.H. Immune modulation of the hypothalamic-pituitary-adrenal (HPA) axis during viral infection. Viral Immunol. 2005, 18, 41-78. [CrossRef] [PubMed]

24. Whitworth, J.A.; Stewart, P.M.; Burt, D.; Atherden, S.M.; Edwards, C.R. The kidney is the major site of cortisone production in man. Clin. Endocrinol. 1989, 31, 355-361. [CrossRef]

25. Ranabir, S.; Reetu, K. Stress and hormones. Indian J. Endocrinol. Metab. 2011, 15, 18-22. [CrossRef] [PubMed]

26. de Vries, E.M.; Fliers, E.; Boelen, A. The molecular basis of the non-thyroidal illness syndrome. J. Endocrinol. 2015, 225, 67. [CrossRef]

27. Economidou, F.; Douka, E.; Tzanela, M.; Nanas, S.; Kotanidou, A. Thyroid function during critical illness. Hormones 2011, 10, 117-124. [CrossRef]

28. Elbers, L.P.B.; Fliers, E.; Cannegieter, S.C. The influence of thyroid function on the coagulation system and its clinical consequences. J. Thromb. Haemost. 2018, 16, 634-645. [CrossRef] [PubMed]

29. Swiatkowska-Stodulska, R.; Skibowska-Bielinska, A.; Wisniewski, P.; Sworczak, K. Activity of selected coagulation factors in overt and subclinical hypercortisolism. Endocr. J. 2015, 62, 687-694. [CrossRef] [PubMed]

30. Kastelan, D.; Dusek, T.; Kraljevic, I.; Polasek, O.; Giljevic, Z.; Solak, M.; Salek, S.Z.; Jelcic, J.; Aganovic, I.; Korsic, M. Hypercoagulability in Cushing's syndrome: The role of specific haemostatic and fibrinolytic markers. Endocrine 2009, 36, 70-74. [CrossRef] [PubMed]

31. Stuijver, D.J.; van Zaane, B.; Feelders, R.A.; Debeij, J.; Cannegieter, S.C.; Hermus, A.R.; van den Berg, G.; Pereira, A.M.; de Herder, W.W.; Wagenmakers, M.A.; et al. Incidence of venous thromboembolism in patients with Cushing's syndrome: A multicenter cohort study. J. Clin. Endocrinol. Metab. 2011, 96, 3525-3532. [CrossRef]

32. Mancini, T.; Kola, B.; Mantero, F.; Boscaro, M.; Arnaldi, G. High cardiovascular risk in patients with Cushing's syndrome according to $1999 \mathrm{WHO} / \mathrm{ISH}$ guidelines. Clin. Endocrinol. 2004, 61, 768-777. [CrossRef] [PubMed] 
33. Connolly-Andersen, A.M.; Whitaker, H.; Klingstrom, J.; Ahlm, C. Risk of Venous Thromboembolism Following Hemorrhagic Fever With Renal Syndrome: A Self-controlled Case Series Study. Clin. Infect. Dis. 2018, 66, 268-273. [CrossRef] [PubMed]

34. Connolly-Andersen, A.M.; Hammargren, E.; Whitaker, H.; Eliasson, M.; Holmgren, L.; Klingstrom, J.; Ahlm, C. Increased risk of acute myocardial infarction and stroke during hemorrhagic fever with renal syndrome: A self-controlled case series study. Circulation 2014, 129, 1295-1302. [CrossRef] [PubMed] 